This is the author's final, peer-reviewed manuscript as accepted for publication. The publisher-formatted version may be available through the publisher's web site or your institution's library.

\title{
Kansas legislators prioritize obesity, but overlook nutrition and physical activity issues
}

Katie M. Heinrich, Mellina O. Stephen, Katherine B. Vaughan, Melinda Kellogg

\section{How to cite this manuscript}

If you make reference to this version of the manuscript, use the following information:

Heinrich, K. M., Stephen, M. O., Vaughan, K. B., \& Kellogg, M. (2013). Kansas

legislators prioritize obesity, but overlook nutrition and physical activity issues. Retrieved from http://krex.ksu.edu

\section{Published Version Information}

Citation: Heinrich, K. M., Stephen, M. O., Vaughan, K. B., \& Kellogg, M. (2013). Kansas legislators prioritize obesity but overlook nutrition and physical activity issues. Journal of Public Health Management \& Practice, 19(2), 139-145.

Copyright: (c) 2013 Lippincott Williams \& Wilkins, Inc.

Digital Object Identifier (DOI): doi:10.1097/PHH.0b013e318254cc57

\section{Publisher's Link:}

http://journals.Iww.com/jphmp/Abstract/2013/03000/Kansas_Legislators_Prioritize_Obe sity_but_Overlook.6.aspx 
Kansas Legislators Prioritize Obesity, but Overlook Nutrition and Physical Activity Issues

Katie M. Heinrich, PhD, ${ }^{1}$ Mellina O. Stephen, MPH, ${ }^{1}$ Katherine B. Vaughan, MPH, ${ }^{1}$ Melinda Kellogg 1

${ }^{1}$ Department of Kinesiology, Kansas State University, Manhattan, KS

Corresponding Author: Katie M. Heinrich, PhD, 1A Natatorium, Department of Kinesiology, Kansas State University, Manhattan, KS 66506; email: kmhphd@ksu.edu; phone: (785) 532-7771 


\begin{abstract}
State-level policymakers play an important role in the fight against obesity due to their ability to create policies that influence opportunities for physical activity and nutrition. Objective: In 2011, we investigated how Kansas policymakers regarded obesity, nutrition and physical activity in comparison to other issues. Design: This study used a cross-sectional design. Setting: This study was conducted in Kansas, a predominately rural and Republican Midwestern state. Participants: All 181 state-level policymakers in Kansas were mailed a cover letter and survey. Main Outcome Measures: Policymakers were asked to identify and rate the importance of issues or problems in need of attention for Kansas. The 2011 state legislative report was content analyzed and coded to match the survey. Comparisons were made by political party. Results: Of the 49 policymakers who completed a survey, 37 were Republicans and 43 were elected to their position. Although obesity was rated second highest behind jobs, physical activity and nutrition-related issues were not seen as important problems; as well, little corresponding legislation was introduced. Other key issues identified by policymakers included budget/spending/taxes, education, jobs/economy, and drug abuse, with more legislation reflecting these problems. Democrats ranked 11 issues as more significant problems than did Republicans: quality of public education, poverty, access to healthcare, lack of affordable housing, ethics in government, lack of public health training, access to healthy groceries, lack of pedestrian walkways/crosswalks/sidewalks, pedestrian safety, air pollution, and global warming $(P<.05)$. Conclusions: There is a need to provide more public health education on the relationship between nutrition and physical activity issues and obesity for Kansas policymakers. Issues identified may be similar for other predominately rural and Republican states. Keywords: Policy, Obesity, Environment, Nutrition Policy, Motor Activity
\end{abstract}


Public policy provides structure and guidance to influence behaviors. ${ }^{1}$ Different types of policy, such as regulations, budget priorities, legislation, and even informal rules all have a larger reach than individual-level efforts on the health of the public. ${ }^{2}$ Competing interests for policymakers include political, economic and social influences. ${ }^{3}$ For example, existing evidence demonstrates the influence of constituent advocacy on the decisions of policymakers. In an examination of the effect of public opinion on funding for tobacco control programs within several states, Snyder and associates ${ }^{4}$ found that greater public support (as measured by a public opinion index) was significantly related to funding allocation. Thus, understanding policymakers’ priorities and perceptions of pressing issues to address within a community is critical to influencing public health.

Obesity, poor nutrition and physical inactivity are major public health problems. Surveillance data indicate a dramatic increase in overweight and obesity prevalence in both children and adults over the past 20 years. ${ }^{5}$ In 2008, one-quarter of the United States (US) population reported no leisure time physical activity at all ${ }^{6}$ and only $14 \%$ of US adults met fruit and vegetable recommendations in $2009 .^{7}$ These statistics have important implications as the prevalence of preventable chronic disease as well as the costs of health care and health care spending continue to increase.

Policy and environmental changes at the community level are recommended strategies for obesity prevention. ${ }^{8}$ Adequate and healthy nutrition are important for preventing as well as treating obesity, and are influenced by many factors. ${ }^{9-10}$ However, these factors are sometimes out of an individual's control. Public policy can influence nutrition by affecting the types of fresh food and produce available in grocery stores, availability of farmers markets, agricultural policies, and ease of access to the grocery store or market. ${ }^{11}$ 
A community's built environment has a significant influence on its citizens' physical activity behaviors. ${ }^{8}$ Policies that initiate, enforce, and regulate changes to the built environment are effective and sustainable in affecting residents' health behaviors because they create lasting infrastructure changes that affect entire communities. ${ }^{12-13}$ Communities implement policies to ensure street connectivity, generate construction of walking and biking trails, street and sidewalk redesign, mixed-use zoning that provides proximal pedestrian destinations, and Safe Routes to School projects. ${ }^{13-14}$ Neighborhoods and cities that are designed to support physical activity through well-designed infrastructure and a positive social environment foster increased physical activity behaviors among inhabitants. ${ }^{15-17}$ Despite evidence that walkable and connected neighborhoods promote physical activity, sprawling neighborhood designs are common, and have shown evidence of higher rates of obesity and overweight as well as inadequate levels of physical activity among residents. ${ }^{18}$ To address these issues, the United States Environmental Protection Agency recommends eleven fixes for urban and suburban zoning codes that encourage smart growth (e.g., allow mixed land use, standards for walkable places) ${ }^{19}$ as well as six livability principles to encourage sustainable rural communities (e.g., investing in walkable neighborhoods, promoting mixed use developments). ${ }^{20}$

How do policymakers regard these issues related to obesity? A survey of Hawaii policymakers found that state and county officials did not regard physical activity and nutritionrelated issues as important concerns, while increasing traffic and poorly planned development and sprawl were among the most highly-rated problems. ${ }^{21}$ Few rated obesity as an important problem, despite the 57.2\% of Hawaii adults who were overweight or obese. However, another study with policymakers provided evidence that perceptions of the importance of obesity-related issues could be changed. The West Virginia Walks campaign used a social ecological approach to 
promote physical activity among inactive community members. ${ }^{22}$ A concurrent pilot study investigated the effects of the campaign on problem identification among policymakers. Policymakers' ratings for the importance of pedestrian infrastructure, traffic congestion and sprawl as problems increased significantly post-intervention as a direct result of the campaign.

In Kansas, the $48.5 \%$ of people meeting guidelines for moderate or vigorous physical activity ranks just below the national average of $51.0 \% .{ }^{23}$ Over $64 \%$ of adults are either overweight or obese. ${ }^{24}$ Additionally, only $18.6 \%$ of Kansans report eating fruits and vegetables at least 5 times a day. ${ }^{25}$ Various public health programming in Kansas has directed efforts to increase physical activity participation such as the Capital City Wellness Project, Kansas Kids’ Fitness \& Safety Day, and the Walk Kansas program. Despite these programmatic efforts, accordant policy changes have been lacking. Other legislation has been passed throughout the state that supports healthy lifestyles through preventive measures (eg, statewide smoking ban), so legislators are clearly supportive of policies that improve health. However, it is unclear whether obesity, nutrition, and physical activity are issues of importance to Kansas legislators.

Previous research has identified a need to improve the built food environment through policy changes, ${ }^{26}$ as well as addressing higher rates of obesity and physical inactivity among rural residents. ${ }^{27}$ Kansas is a predominately rural state. On average, population density in Kansas is 32.9 people per square mile as compared to 79.6 nationally. ${ }^{28}$ Nine of the state’s 105 counties contain $57 \%$ of the population, mostly on the east side of the state; the majority of counties are designated as rural or frontier, several with less than 3 people per square mile. Kansas geography directly affects transportation and access to healthcare. ${ }^{28}$ In fiscal year 2011, Kansas had an estimated budget deficit of $\$ 510$ million $^{29}$ and an unemployment rate of $6.8 \%$ in January $2011.3^{30}$ 
Furthermore, the political affiliation of the respondents is of particular interest in the present study. In the Hawaii study, 46 of out 58 respondents who identified their political affiliation were Democrats. ${ }^{21}$ Kansas is considered a Republican state, as the majority of Kansas residents have been Republican voters since Kansas Statehood in 1861. In 2011, Republican Sam Brownback became Kansas Governor, replacing Democratic leadership since 2003. As well, Republicans held both US Senate and all 4 US Congress seats, all 6 state seats, 32 state senate seats (80\%) and 92 state representative seats (73.6\%) after the 2010 elections. In total, Kansas has 40 senators that serve 4 four-year terms and 125 state representatives that serve two-year terms. The legislative session begins in January and typically lasts for 90 days unless a special legislative session is required. ${ }^{31}$ Consequently, it was of interest to investigate how perceptions on priority problems and issues in Kansas varied based on political affiliation.

The purpose of this study was to understand how issues and problems related to obesity, nutrition and physical activity were rated in comparison to other issues among Kansas policymakers and whether these ratings differed by political party. In addition, we examined the content of all bills introduced during the 2011 legislative session to better understand if the actual legislation discussed matched the perceived importance of each issue.

\section{Methods}

\section{Participants}

Using publicly available information for policymakers in Kansas, names and contact information for all elected officials (eg, governor, senators and representatives) and all gubernatorial appointed officials at state-level departments and agencies were identified, following a similar sampling strategy as Maddock and associates. ${ }^{21}$ This resulted in a population of 181 individuals, including 40 senators, 124 representatives, 2 executive branch members, and 
15 appointed state-level officials (eg, Directors of the Kansas Department of Health and Environment, Kansas Department of Transportation). Forty-nine individuals participated (41 by mail and 8 online), a response rate of $27 \%$. Over $75 \%$ of respondents were Republicans ( $n=37$ ), nine were Democrats (18.4\%), and 3 were members of other political parties (6.1\%). Over eighty percent $(n=43)$ were elected to their position, $10 \%(n=5)$ were appointed, and one did not provide this information.

Measure

The "Survey of Community Leaders" was adapted from the measure used by Maddock and associates. ${ }^{21}$ Participants were first asked an open-ended question allowing them to state the 3 most salient issues or problems in need of attention for Kansas. Participants were next asked to rate 25 common issues or problems faced by states (eg, access to health care, lack of good jobs) on a 5-point scale ranging from "not a problem” to a "problem of extreme importance.” An additional item allowed respondents to state any issues not addressed in the original 25 items. Then, respondents indicated the type of assistance they felt was most needed to address the problems specified in the open-ended question (eg, more legal assistance, more funding). Last, they were asked to specify if their position was appointed or elected and to indicate their political party.

Procedure

Each potential participant was mailed a cover letter describing the purpose of the study and a hard copy of the "Survey of Community Leaders." They were encouraged to complete the survey and return it in a self-addressed prepaid-postage business reply envelope. In addition, a link was provided as an option to complete the survey online. The online survey was made available for 2 weeks and an e-mail reminder was sent to all participants 1 week after the surveys 
were initially mailed. This response time was chosen in order to ascertain policymakers' opinions while the legislature was still in session. All study procedures were approved by the University’s Institutional Review Board.

Responses from both the online and mailed surveys were coded and recorded in SPSS 16 (Chicago, IL). Qualitative survey responses were thematically coded by 2 separate researchers into 11categories (budget/spending/taxes, education, jobs/business/economy, healthcare, social and rehabilitation services/disabled, government regulation/efficiency, environment, retirement, population, immigration, and other). Any discrepancies in coding were discussed until consensus was reached. Means and standard deviations were calculated for the 25 problem ratings. Chisquare analyses were used to make comparisons between political parties. A publicly available summary report of all 2011 state legislation was downloaded from the Kansas Legislature website. ${ }^{32}$ All Senate and House bills, resolutions, and concurrent resolutions and executive reorganization orders introduced or received by the 2011 Kansas Legislature were coded to match the 25 categories (common issues/problems) from the survey. Again, the coding was conducted by two separate researchers. In the case of any coding discrepancies, the full language of the bill was double-checked to verify the appropriate category.

A 2-page, full color policy brief was created from the results and e-mailed back to all 181 policymakers in May. The report summarized the survey results and was designed to highlight obesity, physical activity and nutrition issues.

\section{Results}

One hundred sixty-three issues or problems were written in by participants as most in need of attention in Kansas. Table 1 displays those items by category (note: 2 responses were coded in more than 1 category). Issues related to budget, spending, and taxes accounted for the 
largest group of responses $(21.4 \%, \mathrm{n}=35)$. Over $10 \%$ of participants listed issues relevant to education, jobs/economy, government regulation, and healthcare (12.1-17.0\%, $n=20-28)$. As shown in Table 1, three of the main categories (ie, budget/spending/taxes, education, and healthcare) were further divided into sub-categories to better represent the data.

$<<$ Table 1 about here $>>$

For the 25 common issues or problems participants were asked to rate, lack of jobs, obesity, drug abuse, high taxes, and quality of education were rated the highest, with at least 20\% of participants rating each as a problem of extreme importance (see Table 2). Physical activity and nutrition-related issues were not rated as important problems. In particular, poor nutrition, poorly planned development and sprawl, access to healthy groceries, lack of pedestrian walkways/crosswalks/sidewalks, and lack of recreational facilities had 1 or no respondents that viewed them as problems of extreme importance.

$<<$ Table 2 about here $>>$

When asked to select the type of assistance most needed to solve these problems, $57.1 \%$ $(n=28)$ felt that more active participation from citizens was needed, 10.2\% selected more expert advice or more funding $(\mathrm{n}=5$ each), 2.0\% $(\mathrm{n}=1)$ thought no assistance was needed, $16.3 \%(\mathrm{n}=$ 8) provided other suggestions (eg, legislature capable of and willing to listen and learn, political leaders with guts, significantly lower taxes, and Christian worldview), and $4.1 \%(n=2)$ did not respond to the question.

Comparisons by political party indicated that importance ratings differed significantly for eleven issues. As shown in Table 2, these included quality of public education, poverty, access to healthcare, lack of affordable housing, ethics in government, lack of public health training, access to healthy groceries, lack of pedestrian walkways/crosswalks/sidewalks, pedestrian safety, 
air pollution, and global warming. On average, Democrats rated each of the issues as more important than Republicans $(P<.05)$.

A total of 788 pieces of legislation were introduced or discussed in the 2011 Kansas legislative session. Table 2 lists the categorized bills in order of importance rating from the survey. The most bills were for quality of public education ( $n=100$, issue 5$)$, followed by ethics in government ( $n=73$, issue 11$)$, access to healthcare $(n=68$, issue 9$)$, crime $(n=51$, issue 7$)$, and high taxes ( $n=40$, issue 4). The top-ranked issue, lack of good jobs, was the topic of 19 bills and the third-ranked issue of drug abuse was the topic of 12 bills. Only 1 bill addressed obesity (issue 2), none addressed poor nutrition (issue 12), 12 addressed poorly planned development and sprawl (issue 15), 1 addressed access to healthy groceries (issue 18), 2 addressed lack of pedestrian walkways/crosswalks/sidewalks (issue 20), 5 addressed pedestrian safety (issue 21), and 2 addressed lack of recreational activities (issue 22). Three hundred fifty-one bills did not match the survey categories and were coded as other (ie, government regulations, $n=144$; awards, honors and commendations, $\mathrm{n}=70$; fiscal, $\mathrm{n}=67$; environmental health and utilities; $\mathrm{n}=$ 36, medical and science, $n=22$; phone and internet, $n=6$; and miscellaneous, $n=6$ ).

\section{Discussion}

This study helped identify that Kansas policymakers saw obesity as an important problem, while overlooking physical activity and nutrition. Specifically, obesity was ranked second highest after lack of good jobs, yet the underlying causes of physical activity (ie, poorly planned development and sprawl; lack of pedestrian walkways, crosswalks and sidewalks, pedestrian safety; lack of recreational activities) and nutrition (ie, poor nutrition, access to healthy groceries) did not make the top 10 issues. This may reflect a lack of awareness about

how infrastructure and resources in the built environment impact obesity. ${ }^{11,18,21}$ 
The few Democrats in the sample ranked almost all issues as more important than did Republicans; significantly so for quality of public education, poverty, access to healthcare, , lack of affordable housing, ethics in government, lack of public health training, access to healthy groceries, lack of pedestrian walkways/crosswalks/sidewalks, pedestrian safety, air pollution, and global warming. In Hawaii, only global warming was ranked significantly higher by Democrats. $^{21}$ These data are encouraging in that legislation introduced by Kansas Republicans in these areas would likely also be supported by Democrats.

Issues of perceived importance for survey respondents did not seem to match with actual legislation. For example, the most bills were found for the fifth ranked issue; only 1 bill addressed obesity (ie, to create a task force on obesity prevention and management), but was dead after referral to Committee on Health and Human Services. The high visibility of some issues in the new media including healthcare reform and the need to balance the budget with decreased revenues may have led to more bills being introduced in those areas. As well, policymakers seemed to want to regulate themselves as evidenced by the 73 bills relating to government ethics. Future research could explore linking bill sponsorship with priority ratings.

Poor nutrition was the highest ranked of the physical activity and nutrition issues, yet no bills were identified that addressed it. Other physical activity and nutrition issues ranked in the bottom half; only increasing traffic had a notable number of bills. One explanation for the lack of perceived importance or bills for physical activity and nutrition issues may be due to the emphasis on personal responsibility by many Republican lawmakers in Kansas, where individuals are viewed as controlling their own health through rational choice. Thus, obesity is perceived to result when people make unhealthy choices despite having the self-awareness and necessary means to be healthy. On the other hand, some of the physical activity-related issues 
(eg, lack of pedestrian walkways, crosswalks, and sidewalks) might not have seemed relevant for the many rural areas across Kansas.

The importance of obesity was evident for this group of policymakers, but there is a need to provide more public health education on the root causes. ${ }^{21}$ It also seems that Kansas policymakers would be receptive to both more active participation from their constituents as well as more expert advice. However, translation and dissemination of research results back to policy makers is limited by the degree of isolation between researchers and policymakers, with few researchers highlighting the policy implications of their work. ${ }^{33}$ These efforts could help policymakers understand the importance of policies that help provide environmental changes at the community level by providing resources and infrastructure for healthy nutrition and physical activity opportunities. ${ }^{8}$ Of note, policy efforts that promote personal responsibility, such as policies that reward health behaviors (e.g., dieting) with bonuses while penalizing unhealthy behaviors (e.g., smoking) with higher health insurance premiums. ${ }^{34}$ need to guarantee that individuals have the necessary knowledge, skills, abilities, resources, opportunity, and environmental supports to make the healthy choice. ${ }^{35}$

Reflecting national-level issues, Kansas policymakers are very concerned about money, as fiscal concerns were the most frequently written in response, including budget, spending, and taxes. Kansas is also a major agricultural state and areas of intervention to promote healthy diets include agricultural policies and production practices. ${ }^{11}$ These items influence food availability, price, and quality for consumers. It may be helpful to educate policymakers about the economic costs of physical inactivity and poor nutrition and potential solutions. As well, advocates for policy change could tailor messages to address the ideals for individual responsibility held by many Republicans such as addressing virtues of hard work, delayed gratification, self-respect, 
autonomy, fairness, and self-reliance. ${ }^{36}$ Results from this study are relevant for other states that have predominately Republican leadership and have large proportions of rural areas.

This study adds to the growing literature exploring policymakers' opinions and attitudes around health-related topics in order to help focus advocacy efforts around obesity prevention. Policymakers are looking for legislation that works in the fight against obesity, so they should be receptive to efforts that have been shown to reduce obesity and related health care costs, especially when asked for by constituents. ${ }^{4}$ We directly communicated study results back to policymakers, highlighting their disconnect between seeing obesity as a problem, but not physical activity and nutrition issues, using a colorful policy brief. As noted by Starnatakis and associates, ${ }^{37}$ research results must be transformed into a user-friendly persuasive, professional format for communication to policymakers.

The short survey response time of 2 weeks for policymakers in this study may have served as a limitation, although our response rate was similar to Leyden and associates. ${ }^{22}$ The use of pre-paid business reply envelopes rather than stamped envelopes may have affected our response rate. ${ }^{38}$ It is impossible to determine if those who did respond to our survey systematically differed than those who did not as we did not ask for identifying information other than political party and appointment status. The inclusion of appointed officials may have reflected differing priorities as compared to elected officials’ responsibilities to represent their respective constituencies. Future research might collect additional geographic information for respondents to allow comparisons by region. As well, the legislation coding process we used may have missed bills that contained multiple issues within a single bill.

This study provided a baseline assessment of the current legislative focus in the State of Kansas for the current Republican administration and house. It is encouraging that obesity was 
viewed as a significant problem and that efforts had been initiated to try and address it through prevention and management by a task force. This reflects hard work by several advocacy organizations in Kansas to raise awareness of obesity as a significant public health problem and future state-level efforts to change policies related to physical activity and nutrition should be collaborative efforts that leverage professionals and constituents alike. 


\section{References}

1. Schmid TL, Pratt M, Witmer L. A framework for physical activity policy research. $J$ Phys Act Health. 2006;3:S20-S29.

2. Schmid TL, Pratt M, Howze E. Policy as intervention: environmental and policy approaches to the prevention of cardiovascular disease. Am J Public Health. 1995;85:1207-1211.

3. Bryant T. Role of knowledge in public health and health promotion policy change. Health Promot Int. 2002;17:89-98.

4. Snyder A, Falba T, Busch S, Sindelar J. Are state legislatures responding to public opinion when allocating funds for tobacco control program? Health Promot Pract. 2004;5: 35S-45S. doi:10.1177/1524839904264591

5. Centers for Disease Control and Prevention. U.S. obesity trends: trends by state 19852009. Available at http://www.cdc.gov/obesity/data/trends.html. Accessed March 30, 2011.

6. Centers for Disease Control and Prevention. Physical activity statistics: 1988-2008 no leisure-time physical activity trend chart. Available at http://www.cdc.gov/nccdphp/dnpa/physical/stats/leisure_time.htm. Accessed June 15, 2011.

7. Centers for Disease Control and Prevention. State indicator report on fruits and vegetables, 2009. Available at http://www.fruitsandveggiesmatter.gov/health_professionals/data_behavioral.html. Accessed June 15, 2011. 
8. Kettel Khan L, Sobush K, Keener D, et al. Recommended community strategies and measurements to prevent obesity in the United States. MMWR. 2009;58:1-26.

9. Robinson KT, Butler J. Understanding the causal factors of obesity using the international classification of functioning, disability and health. Disabil Rehab. 2011;33:643-651.

10. Swinburn BA, Caterson I, Seidell JC, James WPT. Diet, nutrition and the prevention of excess weight gain and obesity. Public Health Nutrition. 2004;7:123-146.

11. Hawkes C. Promoting healthy diets and tackling obesity and diet-related chronic diseases: What are the agricultural policy levers? Food Nutrition Bull. 2007;28:S312S322.

12. Brownson RC, Kelly CM, Eyler AA, Carnoske C, Grost L, Handy SL, et al. Environmental and policy approaches for promoting physical activity in the United States: a research agenda. J Phys Act Health. 2008;5:488-503.

13. Heath G, Brownson R, Kruger J, Miles R, Powell KE, Ramsey LT, Task Force on Community Preventive Services. The effectiveness of urban design and land use and transport policies and practices to increase physical activity: a systematic review. $J$ Phys Act Health. 2003;3(S1):S55-S76.

14. Boarnet MG, Anderson CL, Day K, McMillan T, Alfonzo M. Evaluation of the California safe routes to school legislation: urban form changes and children’s active transportation to school. Am J Prev Med. 2005;28(2S2):134-140.

15. Sallis JF, Bowles HR, Bauman A, Ainsworth BE, Bull FC, Craig CL, Sjostrom M, et al. Neighborhood environments and physical activity among adults in 11 countries. Am J Prev Med. 2009;36:484-490. 
16. Hoehner CM, Ivy A, Brennan-Ramirez LK, Handy S, Brownson RC. Active neighborhood checklist: A user-friendly and reliable tool for assessing activity friendliness. Am J Health Promot. 2007;21:534-537.

17. Moudon AV, Lee C, Cheadle AD, Garvin C, Johnson D, Schmid TL, et al. Operational definitions of walkable neighborhoods: Theoretical and empirical insights. J Phys Act Health. 2006;3:S99-S117.

18. Gardner FL, Jalaludin BB. Impact of urban sprawl on overweight, obesity, and physical activity in Sydney, Australia. J Urban Health-Bull NY Acad Med. 2009;86:19-30.

19. United States Environmental Protection Agency. Essential smart growth fixes for urban and suburban zoning codes. EPA 231-K-09-003; 2009. Available at http://www.epa.gov/smartgrowth/essential_fixes.htm. Accessed February 17, 2012.

20. United States Environmental Protection Agency. Supporting sustainable rural communities. EPA 231-K-11-001; 2011. Available at http://www.epa.gov/smartgrowth/pdf/2011_11_supporting-sustainable-ruralcommunities.pdf. Accessed February 17, 2012.

21. Maddock JE, Reger-Nash B, Heinrich K, Leyden KM, Bias TK. Priority of activityfriendly community issues among key decision makers in Hawaii. J Phys Act Health. 2009;6:386-390.

22. Leyden KM, Reger-Nash B, Bauman A, Bias T. Changing the hearts and minds of policy makers: an exploratory study associated with the West Virginia Walks campaign. Am J Health Promot. 2008;22:204-207. 
23. Centers for Disease Control and Prevention. Behavioral Risk Factor Surveillance System Survey Data. 2009. Available at http://apps.nccd.cdc.gov/BRFSS/. Accessed March 30, 2011.

24. Kansas Behavioral Risk Factor Surveillance System. Percentage of adults who are overweight or obese, 2009. Available at http://www.kdheks.gov/brfss/Expansion/index.html. Accessed June 27, 2011.

25. Kansas Behavioral Risk Factor Surveillance System. Percentage of adults reported consuming fruits and vegetables 5 or more times per day, 2009. Available at http://www.kdheks.gov/brfss/Expansion/index.html. Accessed June 27, 2011.

26. Ahearn M, Brown C, Dukas S. A national study of the associations between food environments and county-level health outcomes. J Rural Health. 2011;27:367-379.

27. Patterson PD, Moore CG. Probst JC, Shinogle JA. Obesity and physical inactivity in rural America. J Rural Health. 2004;20:151-159.

28. Kansas Rural Health Options Project. Kansas rural health plan. St. Paul, MN: Rural Health Solutions; 2008. Available at http://krhop.net/documents/KSRHPFinalReport.pfg. Accessed November 8, 2011.

29. Parkinson M. The Governer's State of Kansas Budget Report. Vol. 1, Fiscal Year 2011; 2010. Available at http://budget.ks.gov/publications/FY2011/FY2011_GBR_Volume1--updated_2-102010.pdf. Accessed January 31, 2012.

30. US Bureau of Labor Statstics. Economy at a glance: Kansas. Available at http://www.bls.gov/eag/eag.ks.htm\#eag_ks.f.2. Accessed on January 31, 2012. 
31. Kansas Constitution, Article Two: Legislative. Available at http://www.kslib.info/government-information/kansas-information/kansasconstitution/article-two-legislative.html. Accessed on January 31, 2012.

32. Kansas Legislative Information Systems and Services. 2011 Senate and House actions report and subject index report, final report. June 1, 2011. Available at http://kslegislature.org/li/documents/senate_house_actions_subject_index_20110601.pdf. Accessed June 3, 2011.

33. Brownson RC, Chriqui JF, Starnataki KA. Understanding evidence-based public health policy. Am J Public Health. 2009;9:1576-1583.

34. Ter Meulen R, Jotterand F. Individual responsibility and solidarity in European health care. J Med Philos. 2008;33:191-197.

35. Maree GC. Personal responsibility in Medicaid: challenges and opportunities. [Legislative Briefing] Topeka, KS: Kansas Health Institute; February 19, 2009. Available at http://media.khi.org/news/documents/2009/10/22/021909_Leg_Brief_on_Personal_Resp onsibility.pdf

36. Brown A. If we value individual responsibility, which policies should we favour? J Applied Philos. 2005;22:23-44.

37. Stamatakis KA, McBride TD, Brownson RC. Communication prevention messages to policy makers: the role of stories in promoting physical activity. J Phs Act Health. 2010(S1): S99-S107. 
38. Lavelle K, Todd C, Campbell M. Do postage stamps versus pre-paid envelopes increase responses to patient mail surveys? A randomized controlled trial. BMC Health Serv Res. 2008;8:113. 